\title{
Physicians' Perception Regarding Child Maltreatment In Iran (IR)
}

\author{
B Garrusi, H Safizadeh, B Bahramnejad
}

\begin{abstract}
Citation
B Garrusi, H Safizadeh, B Bahramnejad. Physicians' Perception Regarding Child Maltreatment In Iran (IR). The Internet Journal of Health. 2006 Volume 6 Number 2.
\end{abstract}

DOI: $\underline{10.5580 / 8 \mathrm{c} 1}$

\begin{abstract}
Child abuse is a common social and health problem and because of its wide-ranging effects and implications deserves special attention from the medical and health community. The more severe cases are usually seen in hospitals and clinics; therefore, it is crucial for physicians to be familiar with the common risk factors, manifestations, and diagnostic procedures for child abuse. This survey was performed to assess the knowledge and attitude of practitioners regarding child maltreatment. 197 physicians participated in this survey.

Results showed that $55 \%$ of physicians did not have sufficient knowledge of child abuse.. The attitude towards physical punishment, while negative on the whole, was found to be related to the physician's sex. Although the majority (65\%) of physicians had seen abuse cases in their practice, few had ever reported a case to authorities (4.5\%).

There is a need for organizing educational courses for both medical students and medical practitioners regarding the child abuse.
\end{abstract}

\section{INTRODUCTION}

Despite being the subject of great attention in recent years, the concept of child maltreatment remains difficult to define and study. Some have defined maltreatment on the basis of the perpetrator's intention ${ }_{1}$ : social and cultural factors are very important in determining whether corrective punishment will or will not tend towards maltreatment and physical or psychological abuse ${ }_{2},{ }_{3}$. Apart from cases involving unusual cruelty and violence, many instances of punishment performed within the context of child rearing and education can also be regarded as acts of maltreatment. Even some traditional healing and treatment practices can qualify as examples of abuse. The latter can include cauterization and burning small areas of skin to cure fever, diarrhea or seizures ${ }_{4}$. How frequent is child abuse in Iran? This is difficult to know, since incidence and prevalence studies are lacking and research so far has focused on causes and risk factors in relatively small populations. In 2002, legislation was introduced making child abuse a criminal offense and requiring health professionals to report diagnosed cases to legal authorities. However, loopholes in the law and lack of an adequate social support system have meant that there is limited information on this problem, chiefly from anecdotal reports.
However, looking at the prevalence rates and trends for "collateral" phenomena such as drug addiction, poverty and psychiatric illness has been regarded as an indirect method

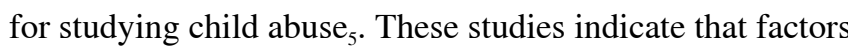
affecting child maltreatment in Iran are similar to those in other countries ${ }_{6}$.

Classic cases of child abuse with multiple injuries pose few diagnostic problems. However, diagnosis can be difficult in cases with minimal physical injury ${ }_{7}$. Therefore, thorough knowledge of the phenomenon of child maltreatment is crucial for general practitioners, as these are often the first members of the health system to come in contact with potential cases. Likewise, the physicians' attitude towards child abuse is an important factor in their diagnosis and management of this problem $_{8}, 9$. This study was performed to assess the knowledge and attitude of general medical practitioners (GP's) in Kerman regarding child maltreatment. We also looked at how cases of abuse are reported to appropriate authorities.

\section{MATERIALS AND METHODS}

This survey involved 200 GP's (out of a total of 288) practicing in the city of Kerman. Data were gathered through 
self-administered questionnaires filled by the physicians at their workplace. The questionnaire included items related to demographic variables, knowledge and attitude regarding child abuse, and reporting of diagnosed cases.

There were 22 questions measuring knowledge; of these, 10 questions targeted knowledge of risk factors and the remaining 12 dealt with signs and symptoms of child abuse. Each question had 3 possible answers: Yes, No, and I Don't Know. We awarded 1 point for every correct answer, zero otherwise. Hence, the total number of points in the Knowledge section ranged from 0 to 22 .

There were 10 questions on attitude, with five possible answers for each question (from Completely Agree to Completely Disagree). We assigned a score of 1 for complete agreement and 5 for complete disagreement, so the total score in the attitude section ranged from 10 (complete agreement with all items) to 50 (complete disagreement with all items). The final section contained 5 questions relating to the physician's attitude and practice in reporting abuse cases.

The questionnaire's face and content validity was assured by a thorough review of current literature and expert opinion. Kronbach's ? for the knowledge and attitude sections was calculated at 0.71 and 0.7 respectively. We used measures of central tendency and dispersion for data description, and ttests plus correlation coefficients for data analysis.

\section{RESULTS}

This survey was done in Kerman ,the largest provinces in Iran (I.R).Out of the 197 completed questionnaires, three had to be discarded because they contained missing data. Sixtyfive percent of the subjects were male and thirty-five percent were female. The mean age was 35.04y ( $\mathrm{SD}=8.14 \mathrm{y})$.

Eighty-eight percent of the physicians were married; $67 \%$ had children, and $63.5 \%$ practiced in a private office, the rest working in State-run and charity clinics. These physicians had an average of 8.01 years' work experience $(\mathrm{SD}=7.56 \mathrm{y}$, range $=1-44 y$ ).

The mean score for knowledge was 16.48 ( $\mathrm{SD}=3.34)$; attitude scores averaged 43.39 , with a standard deviation of 4.12 .

Results indicate that $55 \%$ of respondents do not have adequate knowledge of child maltreatment (correct response rate $<75 \%$ ). The physicians were relatively well informed regarding the causative factors (eg, psychiatric disease in parents) and the physical signs and symptoms, but their knowledge of the psychiatric effects of child abuse was inadequate (Table 1).

\section{Figure 1}

Table 1: Frequency of correct answers to questions assessing physicians' knowledge of child maltreatment

\begin{tabular}{lc} 
I. Questions dealing with risk factors & Frequency (9) \\
\hline Children under 4 years are more likely to suffer maltreatment & $128(65)$ \\
Boys are more likely to suffer physical abuse & $91(46.2)$ \\
Girls are more likely to suffer sexual abuse & $124(62.9)$ \\
Living in poverty can predispose to plysical and sexual abuse & $165(83.8)$ \\
Living in poverty can predispose to neglect & $161(81.7)$ \\
Pluysical and sexual abuse happen more frequently in single-parent & $146(74.1)$ \\
families & \\
Children of educated parents are more likely to suffer physical and & $168(85.3)$ \\
sexual abuse & $103(52.3)$ \\
Neglect happen more frequently in single-parent families & \\
Abuse is more likely in families where at least one parent has a & $166(84.3)$ \\
psychiatric disease & $124(62.9)$ \\
Mentally handicapped children are less likely to suffer abuse & \\
\hline II. Questions related to signs and symptoms of maltreatment & $164(83.2)$ \\
\hline Physical punishment can lead to the child's death & $181(91.9)$ \\
Corporal punishment can cause irreversible physical and mental & \\
damage & $164(83.2)$ \\
Burns on unusual sites can be a sign of abuse & $166(84.3)$ \\
Slin abrasions on unusual sites can be due to abuse & $156(79.2)$ \\
Fractures can be a sign of abuse & $183(92.9)$ \\
Failure to thrive can signify child abuse & $184(93.4)$ \\
Inappropriate social behavior can be a consequence of child neglect & $180(91.4)$ \\
Unusual fear of parents can be a sign of maltreatment & $102(51.8)$ \\
Too much dependence on parents can be a sign of abuse & $148(75.1)$ \\
Seductive behavior in the child can be a sign of sexual abuse & $122(61.9)$ \\
Repeated referral to plysicians (because of treatment failure) can be & $120(60.9)$ \\
relald abuse &
\end{tabular}

Overall, male physicians showed a more negative attitude towards child maltreatment (they tended more towards complete agreement with the statements provided in the questionnaire, $\mathrm{p}<0.05)$. We didn't observe any significant differences between the two sexes in other areas related to knowledge and attitude. The Pearson correlation coefficient showed a positive association between knowledge and attitude towards child abuse $(\mathrm{r}=0.284, \mathrm{p}<0.01)$. We did not detect any correlation between these scores and the individual's age or work experience.(Table2) 


\section{Figure 2}

Table 2: Physicians' Attitude towards Child Maltreatment (n =197)

\begin{tabular}{|c|c|c|c|c|c|}
\hline Items & $\begin{array}{l}\text { Completely } \\
\text { Agree (\%) }\end{array}$ & $\begin{array}{l}\text { Agree } \\
(\%)\end{array}$ & $\begin{array}{c}\text { Neutral } \\
(\%)\end{array}$ & $\begin{array}{c}\text { Disagre } \\
e(\%)\end{array}$ & $\begin{array}{c}\text { Completely } \\
\text { Disagree } \\
(\%)\end{array}$ \\
\hline $\begin{array}{l}\text { Corporal punishunent for bad } \\
\text { behavior }\end{array}$ & $\mathbf{0}$ & $3(1.5)$ & $12(6.1)$ & $98(49.8)$ & $84(42.6)$ \\
\hline Food deprivation for bad behavior & $1(0.5)$ & $9(4.6)$ & $21(10.7)$ & $88(44.7)$ & $78(39.5)$ \\
\hline $\begin{array}{l}\text { Locking up in a roon for bad } \\
\text { behavior }\end{array}$ & 3(1.5) & $12(6.1)$ & $18(9.2)$ & $84(42.6)$ & $80(40.6)$ \\
\hline More severe puuishunent for boys & $4(2)$ & $14(7.1)$ & $9(4.6)$ & $86(43.7)$ & $84(42.6)$ \\
\hline $\begin{array}{l}\text { More frequent punishunent for older } \\
\text { children }\end{array}$ & 2(1) & $15(7.6)$ & $21(10.7)$ & $88(44.7)$ & $71(36)$ \\
\hline $\begin{array}{l}\text { Necessity of corporal puwishunent for } \\
\text { children }\end{array}$ & $1(5)$ & 0 & $13(6.6)$ & 63(32) & $120(609)$ \\
\hline $\begin{array}{l}\text { Creating a fear of "scary" creatures } \\
\text { to control chaldren's behavior }\end{array}$ & 0 & $5(2.5)$ & $8(4.1)$ & $65(33)$ & $119(60.4)$ \\
\hline $\begin{array}{l}\text { Ridiculing / huniliating children for } \\
\text { their mistakes }\end{array}$ & 0 & $1(0.5)$ & $10(5.1)$ & $57(289)$ & $129(65.5)$ \\
\hline $\begin{array}{l}\text { Handicapped children not prone to } \\
\text { psychologic trauna as a result of } \\
\text { physical puuishunent }\end{array}$ & 0 & $8(4.1)$ & $12(6.1)$ & $78(39.6)$ & $99(50.2)$ \\
\hline $\begin{array}{l}\text { Touching / caressing the chald's } \\
\text { genitalia }\end{array}$ & 2(1) & $5(2.5)$ & $8(4.1)$ & $64(32.5)$ & $118(59.9)$ \\
\hline
\end{tabular}

\section{DISCUSSION}

Because of the acute nature of most injuries and the families' inability to treat these at home, the majority of victims are seen by physicians at emergency departments ${ }_{10}$. While severe injuries are easily recognized, the diagnosis may not be so clear in the absence of obvious physical signs- a situation that happens in over $60 \%$ of cases of sexual abuse. For example, over $60 \%$ of sexually abused children do not have any clear-cut symptoms.

In these situations, knowledge of the normal evolution of the child's behavior, and the types of trauma associated with deliberate injury are very important in making the correct diagnosis. There are a number of conditions that can be mistaken for child abuse, and the physician must be perfectly familiar with these situations to avoid trouble for the child and the caregivers. A good knowledge of potential risk factors is a great help in preventing maltreatment during pregnancy, infancy, and early childhood ${ }_{7}$.

Besides its crucial role in prevention ${ }_{11}$, the physician's attitude can be a very important factor in making a diagnosis of child abuse. A study on 157 physicians showed that when the term "child malnourishment" was used without any qualifications, $97 \%$ of physicians considered it as a form of child abuse; in cases where the parents simply forgot to feed the child, only $16 \%$ of physicians branded such malnourishment as child abuse $_{12}$.
Our survey demonstrated that $55 \%$ of GP's do not have sufficient knowledge of child abuse. This shows a greater degree of ignorance compared to another study in Iran, where only $23 \%$ of nurses had inadequate levels of knowledge ${ }_{13}$. The discrepancy could be due to different measuring methods, and the higher level of knowledge expected from physicians.

Studies in Turkey have showed the physicians' knowledge of child maltreatment to be inadequate ${ }_{14},{ }_{15}$. In a similar study on pediatricians and pediatric nurses, $60 \%$ of interviewees had inadequate knowledge of child abuse ${ }_{16}$. Other studies on physicians have also shown low knowledge levels ${ }_{17,8}$. Some workers have

We did not detect any relationship between knowledge levels on the one hand and age and sex on the other. In contrast, some studies have shown higher rates of tentative diagnosis by younger physicians and by female physicians as opposed to male ones ${ }_{4},{ }_{20}$. As women are traditionally more involved with children and older people are generally in favor of harsher upbringing methods, the lack of age and sex associations in our survey could be due to the changing role and status of women in the Iranian society. As women are more and more engaged in jobs outside home, and men become increasingly involved in child nurture and education, differences in knowledge and attitude tend to disappear.

Working experience and time elapsed since graduation did not have an impact on knowledge levels. This shows the inadequacy of continuing education programs for medical graduates, as effective education can improve the physicians' ability to diagnose cases of child abuse ${ }_{19},{ }_{21}$.

Contrary to results from other studies ${ }_{15}$, the place where the physician practiced was not related to knowledge. Most families are reluctant to bring abused children to hospitals, so that many cases of maltreatment are seen by GP's acting as ${ }_{20}$;family" physicians. This means that roughly equal numbers of abuse cases are seen in private and state-run clinics. Another cause may be the fact that all GP's in Iran are graduates of domestic universities, and have received similar education on the problem of child abuse.

Participants in this study had a good degree of knowledge regarding the risk factors (especially the effects of poverty and parental psychiatric disease), with the majority of subjects giving correct answers to the corresponding questionnaire item. This may be a consequence of the reporting of previous abuse cases, the majority of which 
were related to these factors. Alternatively, the trend can be due to the physicians' changing attitudes towards maltreatment of children.

Our physicians were also well informed on the physical signs and symptoms of child abuse (e.g. burns and fractures), but they didn't have a good knowledge of non-physical signs such as severe dependence on parents or inappropriate sexual behavior. Again, education seems to a crucial factor for improving this situation ${ }_{22}$.

There was also a lack of knowledge concerning the importance of unusual genital infection in diagnosing sexual abuse. This is similar to results from other studies that looked at the physicians' skill in diagnosing sexual abuse in pre-pubertal girls by genital examination ${ }_{23}, 24$.

Another study has shown a high degree of agreement between students on the risk factors and physical signs of abuse, but wide discrepancies in diagnosis of cases presenting with psychosocial signs of maltreatment ${ }_{12}$. In this research, physicians were more or less in favor of verbal punishment, but the great majority of them (86\%) opposed corporal punishment. Compared to other studies, our physicians seem to be more averse to the latter type of correction $_{25}$. Some studies indicate that as many as $58 \%$ of physicians (mostly pediatricians) endorse physical punishment $_{26}$.

A crucial factor in making a diagnosis of child abuse is the physician's attitude to child rearing and correction methods $s_{9}$, ${ }_{27}$. A physician with a negative attitude towards a certain type of behavior is more likely to evaluate it as "severely harmful" to the child's physical and mental health ${ }_{26}$. Such negative attitude is usually rooted in the individual's social and cultural background. It should be noted, however, that the present study involved a highly selective group of people and one should be very careful in generalizing its results to the whole society.

Attitudes can also influence knowledge: the lowest level of knowledge in our subjects was recorded in relation to the statement "most cases of abuse involve children under the age of four". This might reflect the society's generally affectionate and lenient attitude towards young children.

There was no significant difference in attitudes towards boys and girls, although gender discrimination is quite common as far as parental behavior is concerned ${ }_{11},{ }_{28}$.

The generally higher attitude scores for female physicians may be explained by the fact that women are generally more involved with children and thus have a better understanding of their problems. However, some authors believe that gender does not have any significant effect on the physician's attitude to child abuse ${ }_{26}$.

In this survey, $65 \%$ of GP's had seen cases of child maltreatment, but only $4.5 \%$ had reported such cases. Failure to report child abuse is not surprising per se $\left[{ }_{18}\right]$, but our results show a more severe degree of underreporting compared to other studies. In addition to well-known causes (such as concerns about the parents' reaction 29 and physician-patient rapport, failure to recognize symptoms ${ }_{20},{ }_{30}$ and physicians' attitudes towards child rearing ${ }_{31}$, an important contributing factor unfamiliarity with legal and administrative mechanisms for reporting child abuse. This is illustrated by the fact that $63.5 \%$ physicians said they would refer abuse cases to forensic authorities. Shortage of effective support and counseling services has meant that most hospitals and clinics refer abuse cases to the police; this contrasts with the situation in neighboring Turkey, where $78.8 \%$ of physicians were aware that abuse cases must be referred to the appropriate social institutions ${ }_{15}$, and $44 \%$ reported such cases to the police ${ }_{14}$ Other studies also show a tendency to refer abuse cases to social institutions rather that the police ${ }_{12}$. Therefore, there is a need to educate physicians on the legal and administrative aspects of reporting child abuse in this country.

Another finding of importance in this study was that $47.5 \%$ of physicians either had no idea of the prevalence of child abuse in Iran, or greatly underestimated the problem. This may be simply due to ignorance, or worse, it may denote a certain indifference toward this scourge of modern societies.

Considering the uniform curriculum and education system in Iran, surveys conducted in other universities are likely to yield similar results. The findings of our surveys once again underline the importance of providing adequate education on diagnosis and etiology as well as the psychological and legal aspects of child abuse. Continuing education programs for practicing physicians can play a major role in raising awareness of this unfortunate phenomenon.

\section{CORRESPONDENCE TO}

B.Garrusi-M.D Assistant Professor of Psychiatry, Department of Community Medicine . Kerman University of Medical Sciences Kerman-Iran TEL:+98341 3224613 FAX:+983413221671 PO.BOX:444 Kerman-Iran(I.R) BGarrusi@kmu.ac.ir

\section{References}

1. Southall DP, Samuels MP,Golden MH. Classification of child abuse by motive and degree rather than type of injury. Arch Dis Child2003;88:101-4

2. Ferrari AM. The impact of culture upon child rearing practices and definitions of maltreatment. Child Abuse \& Neglect 2002; 26:793-813.

3. Bensley L, Ruggles D, Simmons K, Harris C, Williams K, Putvin T, Allen M. General population norms about child abuse and neglect and association with childhood experiences. Child Abuse \& Neglect 2004; 28: 1321-1337. 4. Al-Moosa A, Al-Shaiji J, Al-Fadhli A, Al-BayedK, Adib S. pediatricians`Knowledge, attitude and experience regarding child maltreatment in Kuwait. Child abuse \& 
neglect 2003;27:1161-1178.

5. Madani S. Survey about child abuse trend based on ethiology. social welfare 1382;7:163-189.[Persian]

6. Sayari A. Study about physical child abuse in outpatient pediatric emergency clinic-Tehran. Tavanbakhshi jornal .1380;6-7: 7-13 (Persian)

7. Bullock K. Child abuse, the physicians` role in alleviating a growing problem. American family physician 2000; 15:1-4.

8. Badger LW. Reporting of child abuse, influence of characteristic of physician practice and community. Southern Medical j 1989; 82:281-6.[Abstract]

9. Ashton V. The relationship between attitudes toward corporal punishment and the perception and reporting. Child Maltreatment 2001; 25:389-399.

10. Keshavarz R, Kawashima R, Low CH. Child abuse and neglect presentations to a pediateric emergency department. $\mathrm{J}$ of Emergency Medicine 2002; 23: 3341-3345.

11. Jackson S, Thompson R, Christiansen E, Colman R, Wyatt J, Bockendabl CW,et al. Predicting abuse-prone parental attitudes and discipline practices in a nationally representative sample. Child Abuse \& Neglect 1999; 23: $15-29$.

12. Shore R. Pediatricians in Israeli, factors which affect the diagnisis and reporting of maltreatment children. Child Abuse \& Neglect 1998;22: 143-153.

13. Bastani F . Survey about knowledge of nurses of pediatric wards in educational hospital-Tehran. Journal of nursing and midwifery 1378;20-27

14. Oral R, Can D, Vatansere K, Ozenmis M, Orhar Y. Attitude and knowledge levels of general practitioners and pediatric residents about child abuse and neglect. Turkish pediatry vongres.23-27 oct 1995 Istanbul.

15. Acik Y, Deveci E, Oral R. Level of knowledge and attitude of primary case physicians in Eastern Anatolian cities. In relation to child abuse and neglect. Prevention medicine; [In press].

16. Paavilainer E, Asted-Kurki P, Paunonen-Limonen M.Caring for maltreatment children: a challenge for health care educator. A Adv nurs 2002; 37:551-557.

17. Fung DS, Chow MH. Physicians` and lawyers perspectives of child abuse and neglect in singapore. Medi J 1998; 39:160-165.
18. Von Halringer AR, Dadds M, Armestrong KH. The child abuse lottery. . Child Abuse \& Neglect 1998; 22: 159-169. 19. Erikson MJ, Hill TD, Siegel RM.Barriers to domestic violence screening in the pediateric setting. Pediatrics 2001;108:98-102.

20. Shechter O-S,Tirosh E, Cohen A. Physical abusephysician knowledge and reporting attitude in Israel. Eur $\mathrm{J}$ of Epidemiology 2002; 16: 53-8.

21. Marshal WN, Locke C. Statewide survey of physicians attitude to controversies about chil abuse. Child Abuse \& Neglect 1997; 21: 171-179.

22. Ozturk E, Bingoler BE, Ertem M, Zumrut U, Sevgi G. Medical neglect of child challenges for pediatrician in developing country. . Child Abuse \& Neglect 2002; 26: 757-761.

23. Russell M, Lazenbatt A, Freeman R, Marcones W. Child school abuse. Health professional`s perception, diagnosis and responses. $\mathrm{Br} \mathrm{j}$ community nurs 2004; 9: 332-338. 24. Lantsch K, Johnson CF. Do physician have adequate knowledge of sextual abuse, Survey of practieing physician from 1986-1996. Child Maltreatment 2000; 5: 72-78.

25. Johnson Chales Felzen. Child maltreatment 2002, recognition, reporting and risks. Pediatrics International 2002; 44: 554-560.

26. Tirosh E, Shechter SO, Cohen. Attitude towards corporal punishment and reporting of abuse. Child Abuse \& Neglect 2003; 27: 929-937.

27. Crouch JL, Behl LE. Relationships among parental belifes in corporal punishment, reported stress and physical abuse potential. Child Abuse \& Neglect 2001; 25: 413-419. 28. Myung Sook Park. The factors of child physical abuse in korean immigrant families. Child Abuse \& Neglect 2001; 25: $945-958$

29. Morris JL, Johnson CF, Clasen M. To report or not to report Physician`s attitude toward discipline and child abuse. American J of Disease of Childhood $1985 ; 139$ :

194-197.[Abstract]

30. Flaherty EG, Sege R, Binns J, Mattson CL, Christoffel KK. The pediatric practice research groy health care providers expriance reporting child abuse in the primary care setting. Archives of pediatric and adolescent medicine 2000; 154: 489-493.

31. Giovannoni JM, Becerra RM. child abuse news, free press, 1979 


\section{Author Information}

Behshid Garrusi, M.D.

Psychiatrist-assistant Professor, Social medicine department, Medical school, Kerman Medical Sciences University

\section{Hossein Safizadeh, M.D.}

Social medicine specialist- assistant Professor, Social Medicine Department, Medical School, Kerman Medical Sciences University

Bahram Bahramnejad, M.D.

Social Medicine Department, Medical School, Kerman Medical Sciences University 